\title{
Uma análise da distribuição espacial da produção de cana-de-açúcar no Paraná (1975-2018)
}

\author{
Leonardo Bresolin Galafassi" \\ Romano Augusto Bebber** \\ Pery Francisco Assis Shikida****
}

\begin{abstract}
Resumo
Este artigo analisa as modificações espaciais da produção de cana-de-açúcar no Paraná (1975-2018), a partir do Quociente Locacional (QL) de cada microrregião do estado. Como resultado, as concentrações geográficas iniciais se deram nas microrregiões mais próximas do estado de São Paulo (principal produtor). Posteriormente, com o advento da mecanização da produção agrícola e a consequente possibilidade de se produzir em grande escala, os produtores dessas microrregiões optaram por produzir culturas mais rentáveis e estáveis economicamente, como a soja, o trigo e o milho, marginalizando a cultura da cana-de-açúcar. Com isso, a produção canavieira passou a se concentrar nas microrregiões de Astorga, Cianorte, Paranavaí e Umuarama, onde as condições ambientais são menos favoráveis ao cultivo de grãos.
\end{abstract}

Palavras-chave: cana-de-açúcar; distribuição espacial; Quociente Locacional; Paraná.

* Mestrando no Programa de Pós-Graduação em Desenvolvimento Regional e Agronegócio (PGDRA) da Universidade Estadual do Oeste do Paraná (UNIOESTE). Graduado em Engenharia Agronômica pela ESALQ/USP. E-mail: leonardo.galafassi@hotmail.com

** Mestrando no Programa de Pós-Graduação em Desenvolvimento Regional e Agronegócio (PGDRA) e graduado em Ciências Econômicas pela Universidade Estadual do Oeste do Paraná (UNIOESTE), Campus de Toledo. E-mail: romano.bebber@gmail.com

*** Doutor em Economia Aplicada pela ESALQ/USP. Professor Associado da Universidade Estadual do Oeste do Paraná (UNIOESTE), Campus de Toledo. Docente permanente do Programa de Pós-Graduação em Desenvolvimento Regional e Agronegócio (PGDRA) e do Programa de Pós-Graduação em Economia (PGE). Bolsista de Produtividade em Pesquisa do CNPq. E-mail: peryshikida@hotmail.com 


\section{Introdução}

A fim de expressar a importância econômica da cana-de-açúcar, bem como fundamentar a relevância deste estudo, convém apresentar ao leitor alguns dados interessantes a respeito dessa cultura que vincula distintos encadeamentos produtivos no Brasil e no mundo.

O Brasil figurou em 2018 como o maior produtor mundial de cana-de-açúcar, segundo maior produtor de etanol e o maior produtor de açúcar refinado, sendo São Paulo o estado brasileiro com o maior destaque no setor, tendo produzido 349,2 milhões de toneladas de cana-de-açúcar, seguido por Goiás (70,6 milhões ton.), Minas Gerais (65 milhões ton.), Mato Grosso do Sul (46,9 milhões ton.) e Paraná (37,47 milhões ton.) (BRASIL, 2020). Contudo, esse cenário já foi diferente. Em 2008, o Paraná chegou a ser o segundo maior produtor nacional de cana-de-açúcar, ficando atrás de São Paulo. Ainda assim, o setor canavieiro paranaense detém grande relevância na estrutura produtiva e econômica estadual, sendo responsável por 6,16\% de todo o valor da produção agrícola no Paraná e 5,87\% de toda a área colhida em 2018, figurando como a quarta cultura com maior área colhida, atrás da soja, do milho e do trigo (IPARDES, 2020).

Para entender a importância econômica da cana-de-açúcar, convém destacar que, além de açúcar e etanol, também é possível produzir outros derivados a partir dessa cultura, como melaço, aguardente, bagaço da cana (utilizado para alimentação animal e, sobretudo, cogeração de energia elétrica, por meio de sua queima), dentre outros. O setor exerce importantes encadeamentos econômicos e ambientais: econômicos pelo fato de criar cadeias produtivas diversificadas, considerando as variedades de seus derivados; e ambientais pelo fato de gerar fonte de energia alternativa ao uso de combustíveis fósseis, como a gasolina (derivada do petróleo), para a combustão gerada nos veículos automotores (SANTOS, 2016).

As dinamizações espaciais de uma cultura podem ser reflexos de diversos fatores, como condições edafoclimáticas, estrutura fundiária, preferência por determinada commodity, infraestrutura local, influência de políticas públicas, até interesses econômicos internacionais. Nesse sentido, o objetivo deste artigo é fazer uma análise das modificações espaciais da produção de cana-de-açúcar no Paraná (1975-2018), a fim de entender quais foram os fatores determinantes para tais dinamizações. Para tanto, com o intuito de corroborar as análises, utiliza-se 
o Quociente Locacional (QL) da área colhida, em hectares (ha), da cana-de-açúcar nas microrregiões no estado, calculando também sua participação percentual.

Além dessa introdução, o artigo está estruturado com as respectivas seções: revisão de literatura (2), em que é feito um levantamento geral sobre os fatores pertinentes à distribuição espacial canavieira; metodologia (3), em que é apresentado os procedimentos utilizados no desenvolvimento deste estudo; resultados e discussões (4); e considerações finais, nas quais são expostas as percepções conclusivas deste trabalho.

\section{Revisão de literatura}

Esta seção tem como finalidade apresentar quais fatores podem influenciar as modificações espaciais de um setor produtivo da agricultura, enfatizando os aspectos econômicos e evidenciando os fatores pertinentes ao setor canavieiro, objeto do presente estudo.

A cana-de-açúcar é originária do Sudeste da África e é cientificamente chamada de Saccharum officinarum. Trazida ao Brasil no século XVI, ainda no período colonial, tornou-se uma importante fonte de renda e geração de empregos, destacando-se como uma das principais culturas produzidas no país. Além de ser considerada um produto de importante apreciação na Europa, também foi utilizada como forma de ocupar e defender as terras brasileiras, além de produzir divisas para a Coroa Portuguesa (SZMRECSÁNYI, 1979).

Os primeiros aspectos a serem comentados são relacionados às peculiaridades do ambiente na produção agrícola, a qual se diferencia de outros bens manufaturados devido a fatores como: "( $i$ ) sazonalidade da produção; (ii) influência de fatores biológicos, como doenças e pragas; e (iii) perecibilidade rápida” (ARAÚJO, 2007, p. 18-19).

Em relação à sazonalidade da produção, ou seja, condições climáticas intrínsecas a cada período e região, destaca-se que esta exerce grande influência no produto agrícola, sendo este o motivo de existir a safra e a entressafra, períodos de abundância e períodos em que a produção é insuficiente, respectivamente. Por esse motivo, são escolhidas culturas que se adaptam melhor às adversidades de cada estação do ano, permitindo que as terras sejam fruídas economicamente da melhor maneira possível. Dessa forma, a sazonalidade pode implicar em alguns efeitos para o produtor e o consumidor, como: $(i)$ variações de preços (lei da oferta 
e demanda - preços mais elevados no período de entressafra e mais baixos nos períodos de safra); (ii) necessidade de infraestrutura de estocagem e conservação; (iii) períodos de maior utilização de insumos e fatores de produção; (iv) características próprias de processamento e transformação das matérias-primas; e $(v)$ logística mais exigente e definida (ARAÚJO, 2007).

O segundo fator a ser discorrido diz respeito às condições biológicas das espécies. Tanto no campo quanto após a colheita, os produtos agrícolas estão sujeitos ao ataque de pragas e doenças, o que pode acarretar a diminuição da quantidade produzida e, consequentemente, a diminuição da quantidade ofertada, além de comprometer a qualidade dos produtos (SPERS, 2002).

$\mathrm{O}$ terceiro fator diz respeito à perecibilidade natural. Mesmo após todos os cuidados necessários na produção e no manejo do produto, a atividade biológica continua em ação e, dependendo do produto, sua vida útil pode variar de algumas horas para algumas semanas. Esses são alguns dos fatores que tornam o agronegócio tão complexo, passando a necessitar de uma visão holística, a qual envolve desenvolvimento tecnológico, colheita cuidadosa, classificação e tratamento dos produtos, estruturas apropriadas para armazenagem e conservação, embalagens adequadas, logística, entre outros (ARAÚJO, 2007).

Como qualquer espécie, a cana-de-açúcar possui peculiaridades a serem consideradas no momento de seu cultivo. Em relação aos fatores ambientais, Meneguetti, Mezaroba e Groff (2010) salientam que o clima ideal é aquele que apresenta duas estações distintas, uma quente e úmida, para proporcionar a germinação, o perfilamento e o desenvolvimento vegetativo, seguida de outra fria e seca, para promover a maturação e o consequente acúmulo de sacarose nos colmos. Costa et al. (2005) comentam que os melhores tipos de solos para cultivo são os planos, profundos, porosos e férteis, argilosos ou arenosos. Solos propensos ao encharcamento podem provocar o apodrecimento da planta, e solos muito secos podem provocar a sua morte.

Em relação à localização, algumas regiões podem parecer mais atrativas que outras. Além dos fatores ambientais, as concentrações geográficas também podem ser explicadas por: (i) fatores econômicos, como o crescimento da demanda regional de seus bens, devido ao aumento da renda na área de mercado; (ii) por algum fator estrutural que acarrete uma diminuição do custo de produção; (iii) ou pela distância geográfica de pontos importantes, seja para exportação ou processamento do produto agrícola. 
De acordo com o Instituto de Pesquisa Econômica Aplicada (IPEA) (2010), as interações rurais-urbanas também exercem influência na escolha da região que receberá um investimento. Ou seja, a existência de infraestrutura viária que conecte diferentes regiões em conjunto com interesses regionais, além de aglomerações urbanas, é um fator preponderante na escolha do local.

Segundo Marsden et al. (1993), o processo de reestruturação rural é intrínseco aos seguintes fatores: ( $i$ ) mobilidade do capital; (ii) adoção de um regime de produção mais flexível; (iii) complexidade das relações entre tecnologia e ambiente; (iv) regime de desregulamentação e regulamentação da economia; e $(v)$ novas estruturas políticas. Ou seja, é preciso combinar os efeitos das tendências globais com as ações locais. Quando se considera o setor canavieiro, Guimarães (2009) comenta que um dos principais fatores considerados no momento de escolher a localização das usinas de cana-de-açúcar está ligado à logística de transporte.

Segundo Szmrecsányi (1979), as primeiras unidades produtivas canavieiras no Brasil se instalaram na Região Nordeste e lá se mantiveram concentradas até a década de 1940, quando a produção da cana-de-açúcar no estado de São Paulo passou a se destacar. Os fatores locacionais, as condições edafoclimáticas, a concentração econômica, além de um relativo avanço tecnológico existente em São Paulo, foram os principais fatores que influenciaram na nova concentração geográfica. Para Melo, Esperancini e Silva (2008), essa concentração em torno do estado paulista ocorreu pelo fato de este possuir um parque industrial forte, além de uma base de pesquisa agropecuária consolidada.

São Paulo passou a ser o maior provedor de açúcar, não só de seu próprio mercado em expansão, como também de Estados vizinhos - acessíveis por meio de ferrovias e rodovias - como Goiás, Mato Grosso e Paraná. Assim, na década de 1950, São Paulo tornou-se o principal produtor de açúcar e de álcool entre as unidades da federação brasileira, derrubando a primazia de Pernambuco, que vingava desde o período colonial (MOREIRA, 2013, p 21).

A concentração em torno de São Paulo está correlacionada, também, ao custo de transporte, o qual influencia no preço do insumo, que, por sua vez, influencia no custo de produção e no preço final. Conforme Serra (2010), dois dos principais aspectos que influenciam no maior ou menor avanço das lavouras canavieiras são a localização de usinas de açúcar e álcool, as quais devem estar numa distância não superior a 50 quilômetros das lavouras, e o comportamento do mercado. Segundo Bastos, Landell e Miranda (2016), o transporte é responsável por 32\% do 
custo total da produção, ou seja, é uma despesa relevante que deve ser levada em consideração.

Nesse contexto, percebe-se que o espaço produtivo, composto por agricultura e pecuária, vem seguindo uma dinâmica espacial que tem como fatores preponderantes, além do custo de transporte, a ampliação da produtividade (objetivando as exportações) e a circulação de mercadorias e informações. Esse intenso processo de transformação, verificado no espaço agrário, deve-se à acentuação da integração com as esferas econômica, social e cultural de um território em crescente articulação global (THÉRY, 2017).

Quando se fala em articulação dos setores produtivos no âmbito nacional ou internacional, a atuação do Estado é fundamental, pois este possui prerrogativas intrínsecas que são essenciais na regulação das relações econômicas. De acordo com Lima e Pitaguari (2005), respaldados nos ensinamentos de John Maynard Keynes, existem duas razões principais para a intervenção do Estado na economia: (i) oferecer um ambiente propício para que as forças econômicas realizem todas as potencialidades de sua produção; e (ii) corrigir os defeitos do sistema capitalista, evitando que este venha a ruir.

Para Omar (2001), uma justificativa para a intervenção do Estado na economia é a presença de informações incompletas. $O$ autor comenta que a informação é cara e não é fácil de ser transferida de um agente ao outro, e a presença de informação incompleta, no sentido de que os produtores poderiam saber mais do que os consumidores, ou vice-versa, poderia levar ao fracasso de diferentes mercados. Conforme Shikida e Souza (2009), essa necessidade de comunicação implica, recorrentemente, em uma concentração geográfica de determinadas atividades, considerando que os custos de comunicação podem vir a crescer em distâncias longínquas.

\section{O setor canavieiro no Paraná: uma breve contextualização}

Desde o início de suas atividades econômicas no país, o setor canavieiro vivenciou diversas oscilações, experimentando fases de ascensão e retração econômicas. Contudo, foi em 1933 que ocorreu um dos fatos mais relevantes para a atividade em questão: a criação do Instituto do Açúcar e do Álcool (IAA), o qual passaria a controlar o setor canavieiro brasileiro. Esta foi uma reivindicação dos senhores de engenhos, de usinas e de fornecedores, pois havia a necessidade da existência de um órgão intermediador dos negócios por eles praticados, uma vez que não havia, 
até então, uma simetria de interesses, nem de recursos, capacitações e/ou comportamentos entre os produtores nacionais, o que dificultava o crescimento setorial (SHIKIDA, 1997).

O agronegócio sempre foi um setor relevante economicamente para o Paraná. Em 1940, o estado era o maior produtor cafeeiro, ocupando quase todo o território apto a este cultivo, tornando-se um polo de atração de fluxos migratórios internos, os quais foram, predominantemente, responsáveis por quadruplicar a população estadual em um intervalo de 20 anos. Em 1960, todo o solo paranaense propício ao cultivo do café já havia se esgotado; a produtividade crescia cada vez mais, em ritmo acelerado, que a própria demanda. Como consequência ao excesso de oferta, o preço do café começou a cair. Essa redução de preço desencadeou uma série de medidas tomadas pelo Estado no sentido de desestimular a atividade cafeeira, incentivando os agricultores a optar por outras culturas mais seguras e rentáveis. Foi nesse contexto, a partir da crise do café, ocorrida em meados de 1960, que o setor canavieiro iniciou sua expansão no território paranaense, sendo, portanto, uma alternativa apresentada aos produtores do estado (GARDENAL, 2019; SERRA, 2010).

Conforme comentam os autores Melo, Esperancini e Silva (2008) e Shikida e Alves (2001), ainda que as primeiras plantações de cana-de-açúcar no Paraná remontem ao século XVII, na faixa litorânea, o setor não apresentou nenhuma expressão econômica para o estado até final da década de 1960; sendo o açúcar produzido destinado apenas ao consumo interno. Os autores destacam que o setor canavieiro paranaense só experimentou um relevante crescimento produtivo a partir do surgimento do Programa Nacional do Álcool (Proálcool), criado em 1975, o qual será melhor detalhado na seção de resultados e discussões, uma vez que o período de criação deste coincide com o período de análise deste artigo (1975-2018). ${ }^{1}$

\section{Metodologia}

Esta seção tem por finalidade explicar a metodologia utilizada, demonstrando os fundamentos das variáveis e dos indicadores utilizados e buscando entender como estes foram calculados e adaptados à variável escolhida para as análises deste estudo [área colhida, em hectares (ha), da cana-de-açúcar]. A delimitação geográfica deste estudo é o estado do Paraná, enquanto que a delimitação temporal é 
o período 1975-2018, considerando os dados dos seguintes anos: 1975, 1985, 1995, 2005 e 2018.

Os resultados obtidos são dispostos em mapas temáticos, os quais proporcionam ao leitor uma perspectiva otimizada das dinâmicas espaciais aferidas. Os dados coletados são de caráter secundário e foram obtidos a partir de órgãos governamentais, como o Instituto Brasileiro de Geografia e Estatística (IBGE), o Instituto Paranaense de Desenvolvimento Econômico Social (IPARDES), o Instituto de Terras, Cartografia e Geologia do Paraná (ITCG) e o Ministério da Agricultura, Pecuária e Abastecimento (MAPA).

O estado do Paraná possui uma superfície de $199.324 \mathrm{~km}^{2}$, representando 2,3\% do território nacional, e se localiza na Região Sul do Brasil. Segundo definição do IBGE (2020), o Paraná está subdividido em 6 regiões intermediárias e em 39 microrregiões, dentre outras classificações. Optou-se, neste artigo, por trabalhar com as microrregiões, pelo fato de estas possibilitarem uma análise mais aprofundada quando comparadas com as demais. Contudo, com o intuito de deixar o texto menos denso, a subdivisão das regiões intermediárias será eventualmente mencionada, conforme o mapa apresentado na Figura 1.

Figura 1 - Microrregiões e regiões intermediárias do estado do Paraná

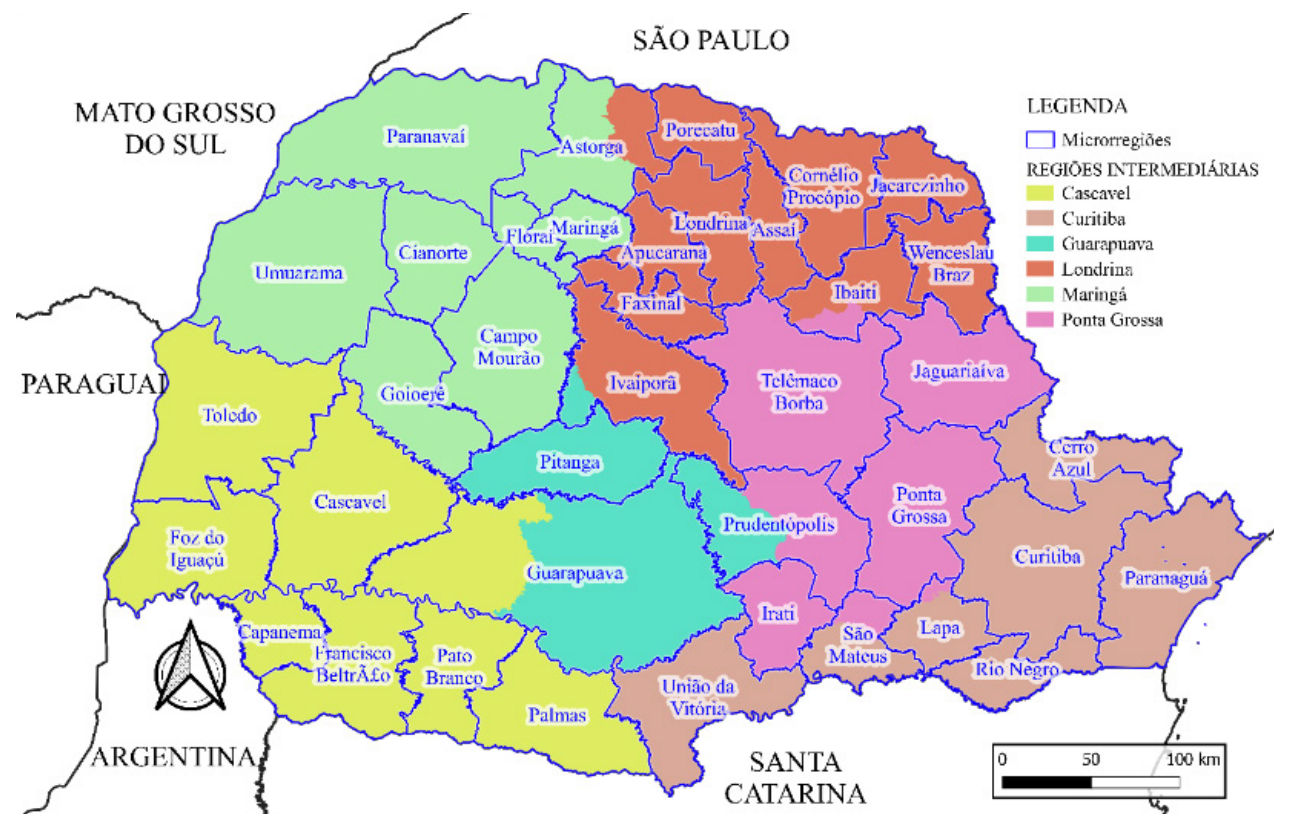

Fonte: elaboração dos autores com base em IBGE (2020). 
O Paraná se caracteriza por regiões distintas, sejam relacionadas ao clima, ao relevo ou aos tipos de solos. Estes e outros inúmeros aspectos fazem com que algumas culturas sejam preferíveis a outras, tornando algumas regiões especializadas em determinada cultura. Considerando esse contexto, a partir da especialização regional, optou-se por utilizar o Quociente Locacional (QL) com o intuito de entender o comportamento das áreas colhidas (ha) da cana-de-açúcar e identificar as microrregiões mais especializadas. Inicialmente desenvolvido para quantificar índices do mercado de trabalho, o QL ganhou notoriedade em outros segmentos, inclusive na agropecuária, pelo fato de proporcionar uma análise mais abrangente de seus resultados (ALVES, 2012).

Nesse sentido, o termo "especialização" pode ser interpretado como uma medida comparativa entre diferentes regiões, considerando um determinado setor produtivo. Segundo Paiva (2006), a especialização de uma região em um ou mais segmentos produtivos é concebida como condição de desenvolvimento desde Adam Smith. Nesse contexto, Alves (2012) destaca que, quando se identifica a aptidão de uma região para uma determinada cultura, também se identifica o potencial que esta possui neste setor produtivo, que, caso fomentado, pode vir a gerar um maior benefício por unidade de custo.

Os valores do QL foram obtidos para cada microrregião por meio da seguinte equação:

$$
Q L=\frac{A D_{i j} / A D_{i t}}{A D_{t j} / A D_{t t}}
$$

Em que:

$A D_{i j}$ = área colhida da cana-de-açúcar na microrregião;

$A D_{i t}$ = área colhida da cana-de-açúcar no Paraná;

$A D_{t j}$ = área colhida das nove principais culturas na microrregião;

$A D_{t t}$ = área colhida das nove principais culturas no Paraná.

Conforme verificado a partir da equação exposta, o cálculo do QL envolve a comparação com a área colhida de outros setores produtivos. Destarte, este artigo faz o comparativo entre a área colhida da cana-de-açúcar e a área colhida das nove principais culturas paranaenses, as quais, desde 1975, ocupam 95\% da área total destinada ao plantio, quais sejam: algodão, arroz, cana-de-açúcar, feijão, mandioca, milho, soja, trigo e café. Sendo assim, o QL é a razão entre a área colhida de cana na microrregião $\left(A D_{i j}\right)$ e a área colhida de cana no estado do Paraná $\left(A D_{i t}\right)$, sobre 
a razão entre a área total colhida das nove principais culturas na microrregião $\left(A D_{t j}\right)$ e a área total colhida destas no estado $\left(A D_{t t}\right)$. Assim, a importância da cultura para cada microrregião é representada quando o valor do QL for superior a 1 , figurando como uma região especializada. A fim de corroborar as análises, a importância de cada microrregião no cultivo de cana está demonstrada, também, a partir da percentagem ocupada por estas na área total colhida no estado (ALVES, 2012).

\section{Resultados e discussões}

O primeiro período a ser analisado é 1975-1985. Conforme comentado, os produtores paranaenses estavam em busca de alternativas para se reerguerem economicamente, considerando as consequências causadas pela crise do café (PRIORI et al., 2012). Esse fator incentivou a expansão da cana-de-açúcar no estado, principalmente nas regiões de divisa com São Paulo, que há anos já se consolidava como um grande produtor nacional dessa cultura (SHIKIDA, 2014).

O surgimento do Grupo Atalla (1972) e Dacalda (1970), empresas do setor sucroalcooleiro detentoras de complexos usineiros, foi um fator relevante para que as microrregiões de Porecatu, Cornélio Procópio, Jacarezinho e Astorga, na região intermediária de Londrina, representassem, juntas, 65\% de toda a área colhida de cana-de-açúcar no Paraná, conforme se percebe no mapa apresentado na Figura 2.

Figura 2 - Quociente Locacional e proporção percentual da área colhida (ha) da cana-de-açúcar nas microrregiões do estado do Paraná em 1975

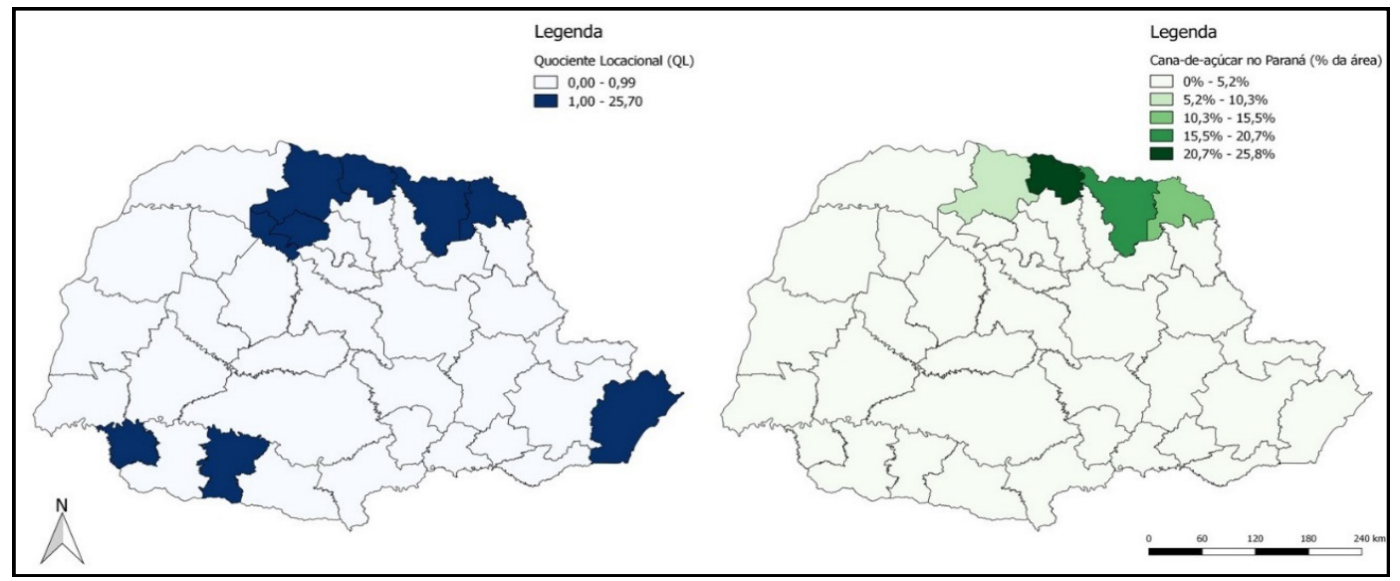

Fonte: elaboração dos autores com base em IBGE (1975). 
Conforme se percebe a partir da Figura 2, as microrregiões especializadas (QL $\geq 1$ ) são, além daquelas já citadas anteriormente, as microrregiões de Floraí, Maringá, Paranaguá, Pato Branco e Capanema. Devido à pouca área destinada para cana-de-açúcar no Paraná e ao baixo desenvolvimento em outras culturas, as regiões de Pato Branco e Capanema acabaram se caracterizando como especializadas no período estudado. Contudo, a pouca produção era direcionada predominantemente para a alimentação animal e a comercialização do açúcar mascavo, representando menos de 5\% da área destinada à cana no Paraná (TOMASETTO; LIMA; SHIKIDA, 2009).

Já para a microrregião de Paranaguá, observa-se que a proporção percentual da área destinada à cana-de-açúcar é 25 vezes maior do que a da área destinada à cana-de-açúcar na região de referência (estado do Paraná). Dois fatores importantes para esta especialização podem ser observados: o primeiro se deve ao fato de essa região ser tradicionalmente caracterizada pela produção de cachaça, produto derivado da cana; e o segundo diz respeito aos fatores intrínsecos à região, como seu relevo montanhoso, por exemplo, o qual faz com que esta microrregião acabe não se destacando na produção agrícola, representando menos de $2 \%$ da área colhida no estado durante todo o período estudado (1975-2018), ou seja, a produção canavieira é comparativamente mais importante vis-à-vis a outras culturas na região (JANNUZZI, 2019).

A partir de meados da década de 1970, alguns fatores impulsionaram, de forma indireta, o avanço da cana-de-açúcar no estado. A expansão do mercado internacional de adoçantes sintéticos colocou em xeque a hegemonia brasileira na exportação de açúcar. Com a baixa demanda, o congênere da cana-de-açúcar sofreu com a queda de preço, ocasionando uma forte pressão política das organizações corporatistas canavieiras ao governo federal, no intuito de que este implantasse algumas políticas públicas que estabilizassem o setor. Concomitantemente, um conflito bélico ocorreu entre países do Oriente Médio, contribuindo para quadruplicar o valor de venda do barril de petróleo. Nesse contexto, com ambas as crises instauradas (petróleo e açúcar), surge, em 1975, o Proálcool, o qual objetivava fomentar a produção de álcool (hoje, etanol), bem como proporcionar estabilidade ao setor canavieiro (SHIKIDA, 2014; SZMRECSÁNYI; MOREIRA, 1991).

Conforme Shikida e Souza (2009), foi a partir do segundo choque do petróleo, em 1979, que o setor canavieiro paranaense se desenvolveu expressivamente. Esse fato, aliado às altas taxas de juros internacionais, fez com que o governo brasileiro acelerasse o uso de álcool hidratado ${ }^{2}$ como principal combustível no país, estimulando a implantação de destilarias autônomas em estados já consolidados no setor, 
assim como em outras regiões onde este setor ainda era incipiente. A produção de álcool figurava como uma fonte alternativa à importação de petróleo, produto o qual o Brasil importava, aproximadamente, $80 \%$ do que consumia. Este estímulo resultou num aumento de $425 \%$ no número de destilarias no Paraná, passando de 4, em 1978/1979, para 21, em 1983/1984.

Em função dos fatores expostos, a área colhida com cana no Paraná aumentou, em 10 anos, 309\%, passando de 45.503 ha para 140.855 ha. Em 1985, a área de maior expressão no estado se manteve nas regiões de Porecatu, Cornélio Procópio, Jacarezinho e Astorga. O Grupo Alto Alegre, localizado na microrregião de Astorga, conseguiu ampliar consideravelmente a área destinada para cana-de-açúcar na região, passando de 3.034 ha, em 1975, para mais de 29.548 ha, em 1985, consolidando a região como a que detinha a maior área colhida no Paraná (20\% da área total).

A palavra que resume esse período é expansão. Com efeito, o álcool combustível, segundo derivado mais importante da cana-de-açúcar, ganhou espaço a partir do Proálcool e se tornou extremamente importante para a matriz energética brasileira. O fácil acesso ao crédito de caráter público e os juros baixos do programa incentivaram a criação de destilarias, além de proporcionarem a expansão do cultivo da cana-de-açúcar mais intensa do que as verificadas nas demais culturas (RAMOS, 2016). Nesse contexto, toda a cadeia produtiva acabou sendo beneficiada, desde usinas, indústrias de máquinas e equipamentos para a produção da cana-de-açúcar, até a indústria automobilística, a qual recebia incentivos para a fabricação de carros movidos a álcool hidratado (SHIKIDA, 2014; BURNQUIST; BACCHI; MAISTRO, 2002).

Quando se analisa o mapa apresentado na Figura 3, percebe-se que houve um aumento no número de microrregiões especializadas $(\mathrm{QL} \geq 1)$. Ou seja, a partir da última grande geada, em 1975, as áreas restantes, destinadas ao plantio do café, foram sendo substituídas gradualmente por outras culturas (ESPECIAL..., 2010). Além das já citadas anteriormente (Porecatu, Cornélio Procópio, Jacarezinho, Astorga e Paranaguá), tornaram-se especializadas as seguintes microrregiões: Ibaiti, Londrina, Faxinal, Maringá, Paranavaí e Cianorte. É possível perceber que houve uma expansão da produção canavieira em direção ao noroeste, consolidando sua importância econômica nas regiões intermediárias de Londrina e Maringá. Serra (2010) destaca que as zonas produtoras de cana-de-açúcar do Paraná se localizam na região intermediária de Londrina, no chamado "Norte Velho" paranaense, desde antes da crise do café, vindo a avançar para a região intermediária de Maringá mais recentemente, a partir do final da década de 1970 . 
Figura 3 - Quociente Locacional e proporção percentual da área colhida (ha) da cana-de-açúcar nas microrregiões do estado do Paraná em 1985

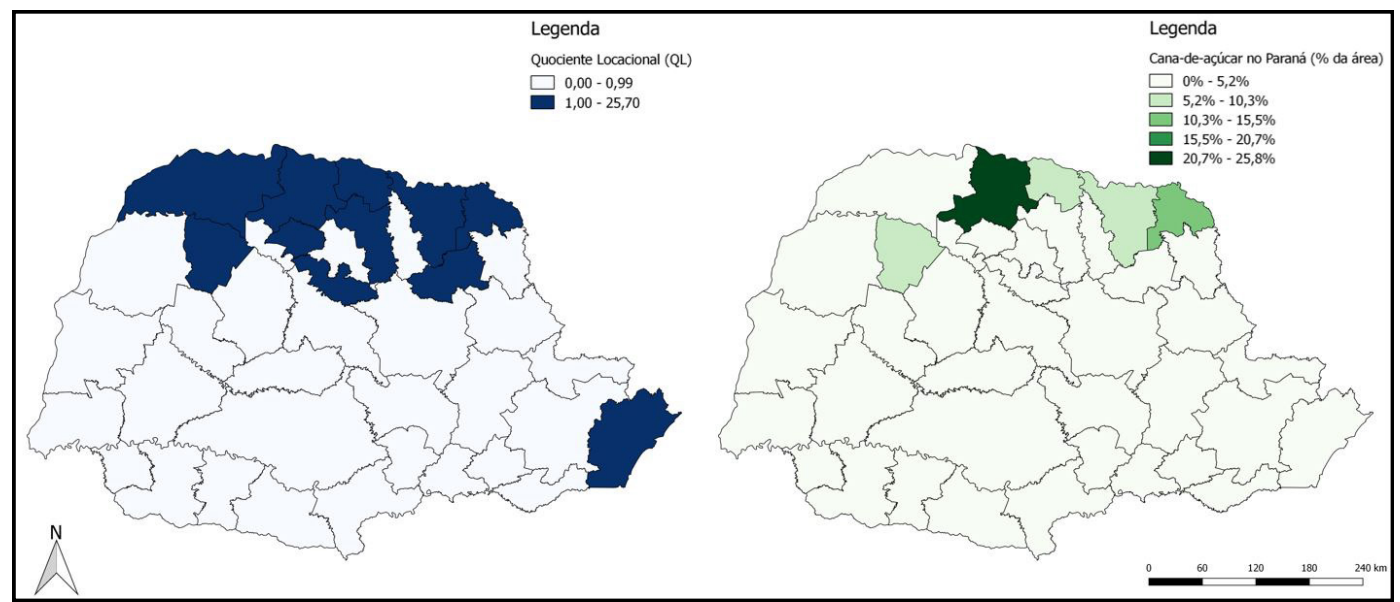

Fonte: elaboração dos autores com base em IBGE (1985).

Para Guimarães (2009), essa dinamização verificada nas últimas décadas nas microrregiões supracitadas se deve, principalmente, ao crescimento expressivo do setor em São Paulo, o qual apresentava uma infraestrutura suficientemente boa, que atendia as demandas do setor produtivo, além de ser um estado que detinha uma grande circulação, seja de bens, pessoas ou informações, o que potencializou os ganhos econômicos de escala.

Conforme destaca Serra (2010), as geadas ocorridas em 1975 contribuíram para a ocorrência de uma concentração fundiária no Paraná, principalmente na região intermediária de Maringá, modificando radicalmente o modelo desenhado pelas colonizadoras, o qual era baseado nas pequenas e médias propriedades. Segundo o autor, com o advento da modernização agrícola, a partir da década de 1970, a ampliação da área de cultivo passou a ser condição necessária para a incorporação de máquinas agrícolas no campo, principalmente tratores. Ou seja, muito em virtude da mecanização, os pequenos proprietários tiveram que vender suas terras aos médios e grandes, incorporando-as às suas lavouras, uma vez que os pequenos proprietários não conseguiriam se manter economicamente, devido às economias de escala, tornando-se, portanto, vulneráveis a esta incorporação. Conforme relatam Gonçalves e Souza (1998), para que o corte mecanizado fosse rentável, era necessário que as propriedades possuíssem, ao menos, 500 hectares, ou um conjunto de propriedades menores interligadas. 
Considerando esse período inicial do Proálcool, Bonan e Kuhn (2012) comentam que seu ápice foi entre 1985 e 1986, quando 96\% da produção nacional era de automóveis movidos a álcool e seu declínio teve início em 1988, quando os preços da gasolina se estabilizaram no mercado internacional.

A crise dos anos 1980, mormente fiscal e inflacionária, também afetou a agropecuária (BACHA, 2012), fazendo com que a área colhida no estado do Paraná caísse $13 \%$ no período 1985-1995. Como esperado, essa crise também afetou a economia canavieira, que teve os incentivos públicos diminuídos consideravelmente, gerando uma crise no Proálcool. Além disso, os motivos que fizeram com que o governo implantasse o programa estavam se invertendo, ou seja, o petróleo voltou a ser competitivo no mercado e o açúcar, a se destacar novamente. Ao mesmo tempo, estava havendo uma baixa adesão dos consumidores aos carros movidos exclusivamente a álcool (BURNQUIST; BACCHI; MAISTRO, 2002; PAULILLO et al., 2007; SANTOS, 2016).

Nesse contexto, as empresas que avançaram no paradigma tecnológico, ante ao subvencionista, sobressaíram-se. Foi o caso do Grupo Santa Terezinha, que, durante o período 1985-1995, expandiu suas operações adquirindo usinas nas microrregiões de Cianorte, Paranavaí e Umuarama, o que fez com que as duas últimas passassem a figurar como grandes produtoras de cana-de-açúcar, conforme é possível visualizar no mapa apresentado na Figura 4 (USACUCAR, 2020).

Figura 4 - Quociente Locacional e proporção percentual da área colhida (ha) da cana-de-açúcar nas microrregiões do estado do Paraná em 1995

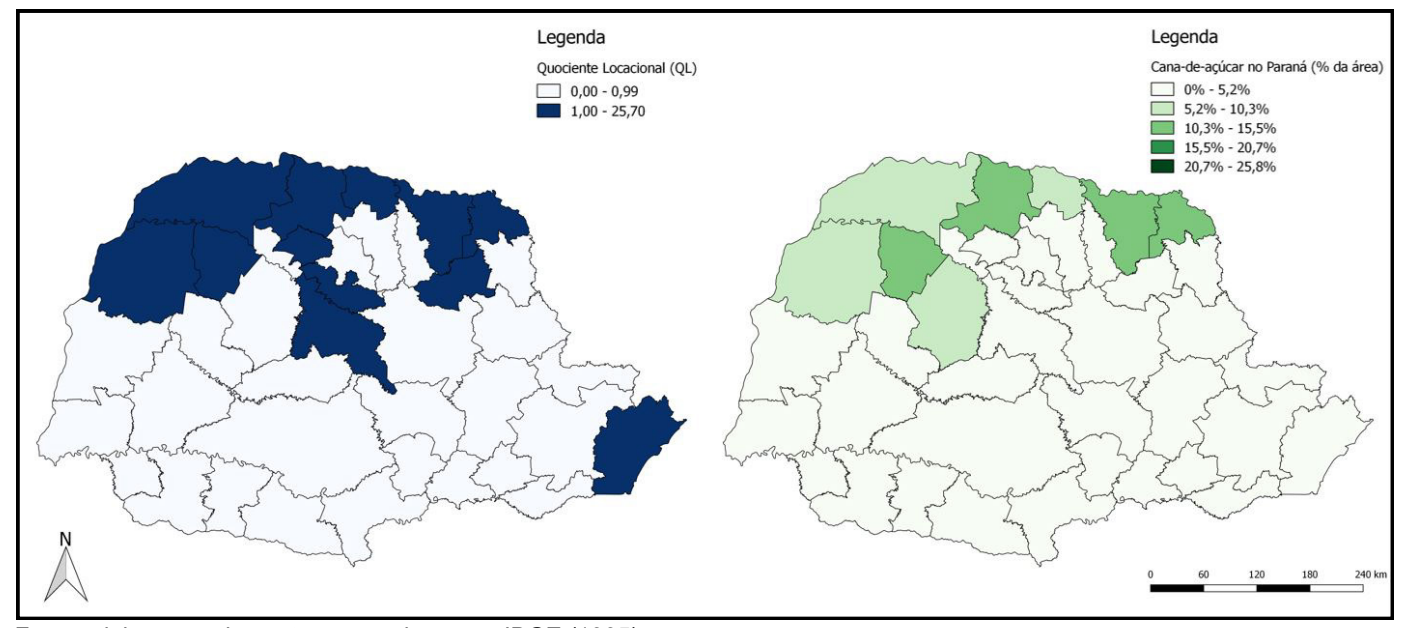

Fonte: elaboração dos autores com base em IBGE (1995). 
A partir da Figura 4, é possível perceber que as microrregiões especializadas na produção da cana-de-açúcar pouco se alteraram, acrescendo apenas as microrregiões de Ivaiporã e Umuarama com $\mathrm{QL} \geq 1$. Com a expansão da soja, a microrregião de Londrina deixou de ser especializada em cana-de-açúcar e passou a se concentrar em maiores áreas destinadas ao cultivo da leguminosa.

A partir do recorrente abandono do Estado ao setor canavieiro, além da extinção de aparatos regulatórios a produção, comercialização e política de preços, intensificados a partir da extinção do IAA, abriu-se caminho para que as usinas mais tecnificadas e dinâmicas pudessem investir e crescer, sendo regulamentadas pelo mercado. Este fator foi fundamental para o amadurecimento do setor, tornando-o mais competitivo (BELIK; VIAN, 2002).

A fim de se expandirem no mercado, os usineiros aderiram ao caráter sustentável da produção canavieira. Com a orquestração do Estado, o processo da queima dos canaviais (o qual consiste em atear fogo no canavial para promover a limpeza das folhas secas e verdes consideradas matéria-prima descartável e facilitar a colheita manual) passou a ser marginalizado, enquanto a colheita mecanizada, ambientalmente benéfica, passou a ser de uso recorrente. Ou seja, além de ser uma fonte de energia renovável (produzida a partir da biomassa), o álcool passou, então, a figurar como um combustível pouco prejudicial ao meio ambiente (VIAN; GONÇALVES, 2007).

Ainda conforme Vian e Gonçalves (2007), um dos principais fatores que possibilitou a mecanização da colheita da cana foi o investimento em tecnologia, que também propiciou o aproveitamento do bagaço na cogeração de energia, da vinhaça para fertilização do solo, automação industrial, etc. A modernização tecnológica paranaense foi consideravelmente impulsionada a partir de técnicas desenvolvidas em São Paulo, as quais foram financiadas pelo crédito rural. Essa difusão tecnológica foi uma conquista importante de empresas estatais de assistência técnica, extensão rural e pesquisa, como a Empresa Brasileira de Pesquisa Agropecuária (Embrapa), a Empresa de Assistência Técnica e Extensão Rural (Emater), o Instituto Agronômico de Campinas (IAC) e a Coordenadoria de Assistência Técnica Integral (CATI).

De acordo com Vieira e Simon (2005), os principais ganhos derivados da colheita mecanizada foram a redução de custo e o aumento da produtividade do trabalho. Ademais, essa mecanização ocorreu em intensidades diferentes nas regiões, sendo a restrição do manuseio dos equipamentos em áreas com maiores aclives e/ ou declives um dos fatores determinantes. 
Em 1997, a partir da vigência do Protocolo de Kyoto (tratado internacional com compromissos mais rígidos para a redução da emissão dos gases que produzem o efeito estufa), vários países se dispuseram a reduzir suas emissões de gases geradores desse efeito, sendo o uso racional dos recursos energéticos disponíveis um dos principais pilares. No mesmo ano, a fim de estimular o setor, o governo federal criou o Conselho Interministerial do Açúcar e do Álcool (CIMA), estipulando a adição de um percentual mínimo à gasolina (hoje o combustível é composto por $25 \%$ de álcool anidro e 75\% de gasolina), o que acabou impulsionando o crescimento dos investimentos no setor canavieiro oriundos, principalmente, do exterior. Os modos de produção sustentáveis e ambientalmente benéficos se difundiram no mercado consumidor e, em 2003, surgiram os primeiros veículos flex-fuel, movidos a gasolina e/ou a álcool, possibilitando a mistura de ambos em qualquer proporção (TETTI, 2002; SHIKIDA, 2014).

A partir de 2005, é possível perceber que a concentração da cana-de-açúcar na região intermediária de Maringá intensificou-se. Juntas, as microrregiões de Astorga, Cianorte, Paranavaí e Umuarama representavam mais de 58\% de toda a área colhida da cana-de-açúcar no Paraná, conforme o mapa apresentado na Figura 5. Em comparação a 1995, a única modificação verificada, em relação ao QL, é que a microrregião de Ivaiporã deixou de ser especializada.

Figura 5 - Quociente Locacional e proporção percentual da área colhida (ha) da cana-de-açúcar nas microrregiões do estado do Paraná em 2005

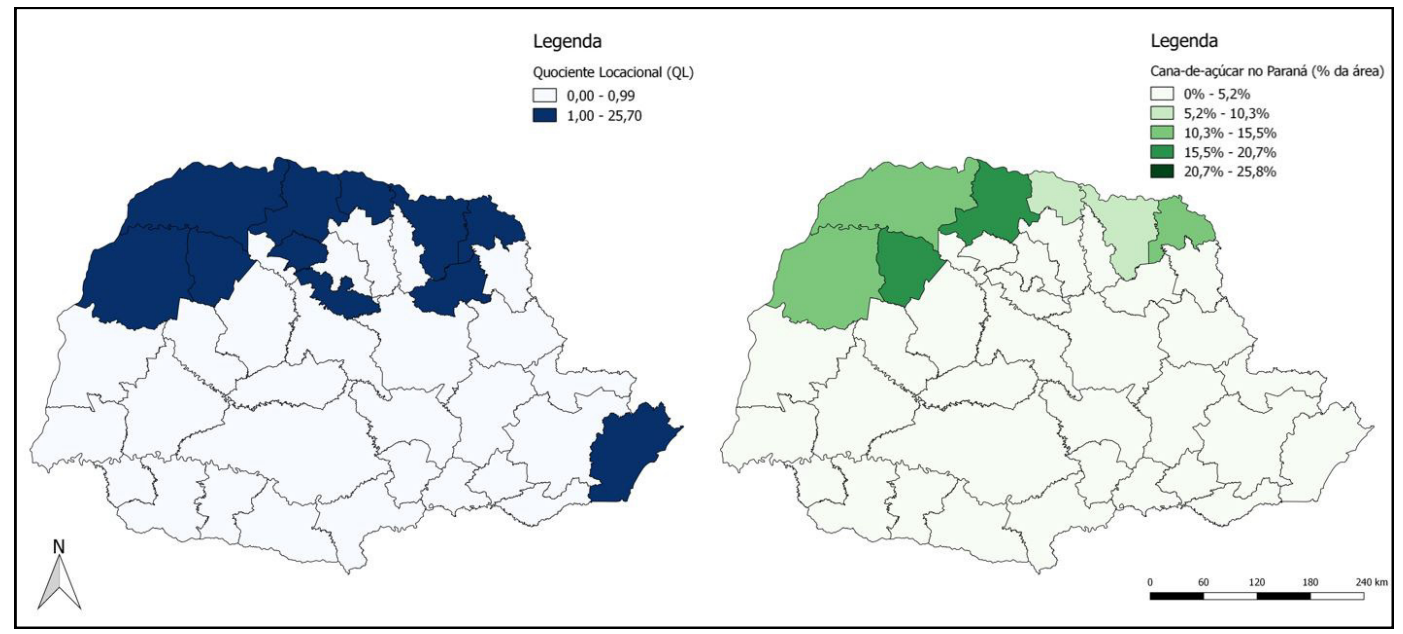

Fonte: elaboração dos autores com base em IBGE (2005). 
Mesmo com o investimento financeiro estrangeiro e diversos aparatos tecnológicos, o álcool teve dificuldades em competir com os combustíveis derivados do petróleo. Com a descoberta do pré-sal e a manutenção artificial dos preços da gasolina pelo governo federal por meio da Petrobras, inúmeras usinas pediram recuperação judicial ou decretaram falência, como o Grupo Ranuka (região de Ivaiporã); Dasa (Cornélio Procópio); Dail Clarion (Ibaiti); Casquel (Jacarezinho); Central do Paraná (Porecatu); e Sabarálcool (duas unidades: Campo Mourão e Umuarama) (GOEBEL et al., 2020).

Com a crise de 2008, os tratos culturais realizados na cana-de-açúcar, como adubação, defensivos químicos, produção de mudas, execução das atividades de pulverização, plantio e colheita, ficaram mais onerosos, tornando a produção economicamente custosa (SHIKIDA, 2014).

Conforme é possível observar a partir do mapa apresentado na Figura 6, a concentração da produção de cana-de-açúcar na região intermediária de Maringá se mostrou mais evidente. Houve uma intensificação da produção nas microrregiões de Astorga, Cianorte, Paranavaí e Umuarama. Considerando o QL, eram regiões especializadas em cana-de-açúcar, em 2018, além das quatro supracitadas, as microrregiões de Porecatu, Jacarezinho, Ibaiti, Faxinal e Paranaguá.

Figura 6 - Quociente Locacional e proporção percentual da área colhida da cana-de-açúcar nas microrregiões do estado do Paraná em 2018

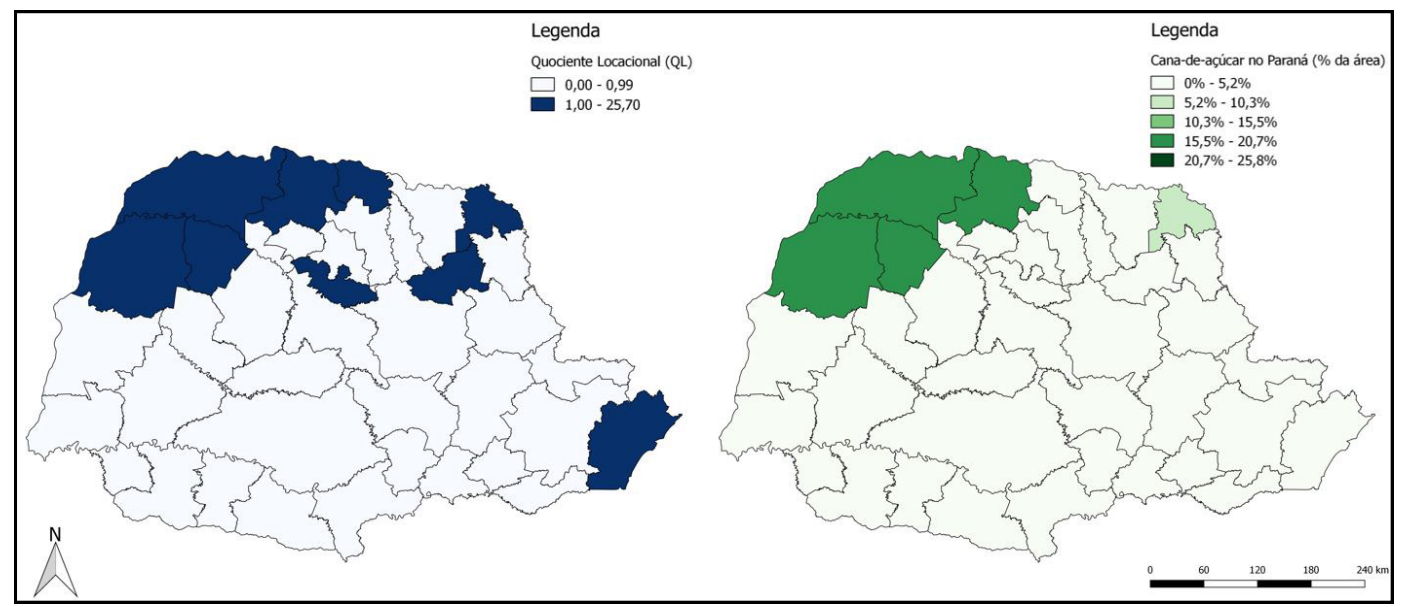

Fonte: elaboração dos autores com base em IBGE (2018). 
Para Paczyk (2009), essa concentração verificada nas regiões intermediárias de Londrina e Maringá ocorreu devido aos investimentos feitos na ampliação das unidades industriais já existentes, cujos objetivos eram reduzir os custos na produção e baratear o combustível. Contudo, para compreender melhor as modificações espaciais verificadas na produção da cana-de-açúcar no período em estudo, convém realizar uma breve análise das condições ambientais relacionadas ao clima e à precipitação do estado do Paraná.

Isso posto, a classificação utilizada no mapa temático do clima (classificação climática de Köppen) é amplamente utilizada por diversos especialistas da área (CARDOSO; MARCUZZO; BARROS, 2014). A região caracterizada em verde, no mapa apresentado na Figura 7, é classificada como Cfa, clima subtropical úmido, ou seja, apresenta média mensal superior a $22 \square \mathrm{C}$ nos meses mais quentes; segundo Meneguetti, Mezaroba e Groff (2010), este é o clima ideal para a germinação, o perfilhamento e o desenvolvimento vegetativo da cana-de-açúcar. Outra classificação que abrange boa parte do estado é a Cfb, em cor amarela no mapa, que possui clima oceânico, e a média mensal da temperatura é inferior a $22 \square \mathrm{C}$ nos meses mais quentes. A temperatura média ideal para se atingir uma boa produtividade e boas taxas de açúcares na planta varia entre $22^{\circ} \mathrm{C}$ e $30 \square \mathrm{C}$ durante o dia. Concomitantemente, sugere-se um índice pluviométrico de 1.200 a 1.300 milímetros ao ano, que é encontrado nas regiões intermediárias de Londrina e Maringá, sendo as mais apropriadas, portanto, ao cultivo da cana-de-açúcar. Além desses fatores, há de se considerar a atratividade econômica das demais culturas, as quais podem vir a ser preferíveis ante a cultura canavieira, considerando o preço comercial praticado (EMBRAPA, 2008).

Figura 7 - Clima e precipitação no estado do Paraná
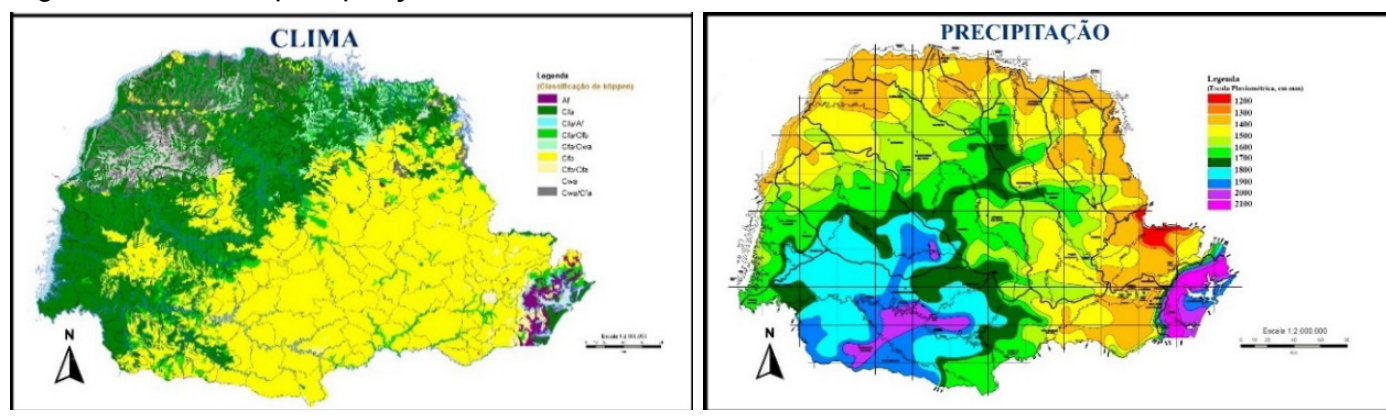

Fonte: ITCG (2020). 
A partir de 2005 e com o fim da abertura e da exploração de novas áreas no estado do Paraná (término das fronteiras agrícolas), o aumento ou o decréscimo na área destinada ao cultivo da cana-de-açúcar se desenvolveu por meio da substituição de outras atividades agropecuárias. Com o crescimento da liquidez de culturas anuais como soja, milho e trigo, além das características pedológicas (solos de origem basáltica), as características da estrutura produtiva da região intermediária de Londrina foram se modificando. Nesse contexto, a cultura canavieira passou a ocupar as áreas de pastagem no arenito (Formação Caiuá) da região intermediária de Maringá (SERRA, 2010). Ou seja, houve uma marginalização do cultivo da cana no Paraná, que não conseguiu, a princípio, competir com o preço praticado pelos grãos, restando apenas as áreas menos propícias à agricultura.

\section{Considerações finais}

Este artigo analisou as modificações espaciais da produção de cana-de-açúcar no Paraná (1975-2018), a partir do Quociente Locacional (QL) de cada microrregião do estado.

Considerando o período de análise, inferiu-se que, inicialmente, a produção de cana-de-açúcar experimentou uma relevante expansão econômica a partir da implantação de programas governamentais, como o Proálcool, o qual proporcionou ao setor canavieiro um ambiente propício ao seu crescimento, mormente a partir de subvenções governamentais. A concentração verificada inicialmente na região intermediária de Londrina é explicada por dois fatores principais: $(i)$ sua proximidade com o estado de São Paulo, o principal produtor nacional dessa cultura; (ii) e devido à proximidade das usinas já existentes na região. Ou seja, a distância entre os agentes econômicos é um fator preponderante para explicar essa concentração geográfica, até porque parcelas das terras paranaenses, ao norte do estado, funcionaram como avanços decorrentes do transbordamento da economia canavieira paulista.

A partir de 1985, o setor canavieiro teve seus incentivos públicos diminuídos consideravelmente, gerando uma crise no setor, sendo que a partir dos anos 1990, com a extinção do IAA, o livre mercado foi a ideologia predominante no setor, arrefecendo-se os mecanismos intervencionistas outrora existentes na atividade. Nesse contexto, as usinas que possuíam uma base tecnológica que propiciasse condições competitivas obtiveram crescimento, mesmo sem o subvencionismo público. 
A partir dos anos 1990, os modos de produção também tiveram que ser adaptados ao conceito da sustentabilidade, difundido no mercado consumidor. Ou seja, quanto menos prejudicial ao meio ambiente, mais interessante o produto ficava. Com o recrudescimento da mecanização/modernização da produção agrícola em geral, o setor canavieiro procurou se adaptar a este novo modo de produção (eliminando cada vez mais a queima de canaviais), intensificando a produção de etanol, minimizando custos e otimizando todo o processo produtivo, buscando avançada capacidade tecnológica que permitisse maior competitividade.

Espacialmente, constatou-se que a área produtiva da cana-de-açúcar experimentou uma expansão na direção noroeste do estado, sendo que as regiões mais expressivas no cultivo da cana-de-açúcar em 1975 foram: Porecatu, Cornélio Procópio, Jacarezinho e Astorga. Em 2018, passaram a ser: Astorga, Cianorte, Paranavaí e Umuarama. Nesse contexto, são vários os fatores que contribuíram para essa dinamização espacial, porém, o principal foi o avanço tecnológico da produção agrícola, uma vez que este modificou severamente a forma de se produzir. Além de corroborar uma reestruturação fundiária, a modernização da produção agrícola condicionou a escolha da cultura a ser produzida em determinada região aos fatores internacionais, além dos fatores ambientais locais. Isto é, a partir do avanço tecnológico e da consequente possibilidade de se produzir em grande escala, objetivando as exportações, os produtores da região intermediária de Londrina optaram por produzir culturas que fossem mais rentáveis e, ao mesmo tempo, mais estáveis economicamente, mitigando sua vulnerabilidade em relação às oscilações de preço e demanda, como era o caso da cana-de-açúcar.

Mesmo sendo substituída por outras culturas com maior liquidez (principalmente soja, trigo e milho), o setor canavieiro encontrou, nas áreas marginalizadas do arenito da região intermediária de Maringá, um atrativo à sua produção. Nesse sentido, retratado também pelo Quociente Locacional, as regiões especializadas $(\mathrm{QL} \geq 1)$ no cultivo da cana-de-açúcar experimentaram modificações espaciais ao longo do período analisado, devido, principalmente, ao crescimento da área destinada às outras culturas, e não simplesmente em função da diminuição da área destinada ao cultivo da cana-de-açúcar.

Por último, mas não menos importante, espera-se que este estudo contribua para futuras pesquisas sobre modificações espaciais da produção de cana-de-açúcar no Paraná, podendo ser ampliada também para outros estados brasileiros, seja com esta metodologia ou com outras. 


\title{
An analysis of the spatial distribution of sugar cane production in Paraná (1975-2018)
}

\begin{abstract}
This article analyzes the spatial changes in the production of sugarcane in Paraná (19752018), based on the Locational Quotient (QL) of each microregion in the State. As a result, the initial geographic concentrations occurred in the micro-regions closest to the State of São Paulo (main producer). Subsequently, with the advent of mechanization of agricultural production and the consequent possibility of producing on a large scale, producers in these micro-regions opted to produce more profitable and economically stable crops, such as soybeans, wheat and corn, marginalizing the cultivation of sugarcane. -of sugar. As a result, sugarcane production started to be concentrated in the micro-regions of Astorga, Cianorte, Paranavaí and Umuarama, where the environmental conditions are less favorable to the cultivation of grains.
\end{abstract}

Keywords: sugar cane; spatial distribution; Locational Quotient; Paraná.

\section{Análisis de la distribución espacial de la producción de caña de azúcar en Paraná (1975-2018)}

\section{Resumen}

Este artículo analiza los cambios espaciales en la producción de caña de azúcar en Paraná (1975-2018), con base en el Cociente de Localización (CL) de cada microrregión del Estado. Como resultado, las concentraciones geográficas iniciales ocurrieron en las microrregiones más cercanas al Estado de São Paulo (principal productor). Posteriormente, con el advenimiento de la mecanización de la producción agrícola y la consecuente posibilidad de producir a gran escala, los productores de estas microrregiones optaron por producir cultivos más rentables y económicamente estables, como soja, trigo y maíz, marginando el cultivo de la caña de azúcar. Como resultado, la producción de caña de azúcar pasó a concentrarse en las microrregiones de Astorga, Cianorte, Paranavaí y Umuarama, donde las condiciones ambientales son menos favorables para el cultivo de granos.

Palabras clave: caña de azúcar; distribución espacial; cociente de ubicación; Paraná.

\section{Notas}

1 Maiores considerações sobre o setor canavieiro no Paraná, ver: Tschá et al. (2010), Montagnhani (2012); Goes (2013) e Bechlin et al. (2020).

2 Existem dois tipos de álcool: o anidro e o hidratado. O primeiro contém uma pureza de 99,3\% (nível de álcool etílico) e sua produção exige maiores custos. Já o hidratado apresenta um nível máximo de 94,3\% (PACZYK, 2009). 


\section{Referências}

ALVES, L. R. Indicadores de localização, especialização e estruturação regional. In: PIACENTI, C. A.; LIMA, J. F. (org.). Análise regional: metodologias e indicadores. Curitiba: Camões, 2012. p. $30-50$.

ARAÚJO, M. Fundamentos de agronegócios. São Paulo: Atlas, 2007.

BACHA, C. J. C. Economia e política agrícola no Brasil. São Paulo: Atlas, 2012.

BASTOS, K. J. J. Z.; LANDELL, M. G. de A.; MIRANDA, E. de S. Influência da cana-de-açúcar no custo do corte mecanizado. Revista IPecege, Piracicaba, v. 2, n. 4, p. 42-59, 2016.

BECHLIN, A. R. et al. Alterações na estrutura produtiva e no mercado de trabalho formal decorrentes da falência de uma agroindústria canavieira em Engenheiro Beltrão e Perobal (PR). Informe Gepec, Toledo, v. 24, n. 2, p. 249-274, jul./dez. 2020.

BELIK, W.; VIAN, C. E. F. Desregulamentação estatal e novas estratégias competitivas da agroindústria canavieira em São Paulo. In: MORAES, M. A. F. D. de; SHIKIDA, P. F. A. (org.). Agroindústria canavieira no Brasil. São Paulo: Atlas, 2002. p. 69-93.

BONAN, P.; KUHN, S. L. Mapeamento da produção da cana-de-açúcar no Brasil, com ênfase no Estado do Paraná e na sua região Noroeste. Revista Brasileira de Energias Renováveis, Curitiba, v. 1, n. 1, p. 122-147, 2012.

BRASIL. Ministério da Agricultura, Pecuária e Abastecimento. Brasília, 2020. Disponível em: https://www.gov.br/agricultura/pt-br. Acesso em: 15 ago. 2020.

BURNQUIST, H. L.; BACCHI, M. R. P.; MAISTRO, M. C. M. Análise da comercialização dos produtos do setor sucroalcooleiro brasileiro: evolução, contexto institucional e desempenho. In: MORAES, M. A. F. D. de; SHIKIDA, P. F. A. (org.). Agroindústria canavieira no Brasil. São Paulo: Atlas, 2002. p. 182-199.

CARDOSO, M. R. D.; MARCUZZO, F. F. N.; BARROS, J. R. Climatic classification of Köppen-Geiger for the state of Goias and Federal District. Acta Geográfica, Boa Vista, p. 40-55, 2014.

COSTA, N. de L. et al. Utilização da cana-de-açúcar na alimentação animal. Recomendações Técnicas, 18. Amapá: Embrapa, 2005.

EMBRAPA. Árvore do conhecimento: cana-de-açúcar. Brasília, 2008. Disponível em: https://www. agencia.cnptia.embrapa.br/gestor/cana-de-acucar/arvore/CONTAG01_10_711200516716.html. Acesso em: 20 set. 2020.

ESPECIAL - 35 anos da geada de 1975 - Entenda o que foi a geada negra que dizimou todas as plantações de café no Paraná. Revista Cafeicultura, 2010. Disponível em: https://revistacafeicultura.com.br/?mat=34022\#: :text=geada\%20de\%201975-,No\%20dia\%2018\%20de\%20julho\%20 de\%201975\%2C\%20uma\%20forte\%20geada,Estado\%20do\%20Paran\%C3\%A1\%20foi\%20destruida. Acesso em: 12 set. 2020.

GARDENAL, L. A. S. Café e atividade industriais no Norte do Paraná: a formação de um complexo cafeeiro? (1940-1970). In: CONFERÊNCIA INTERNACIONAL DE HISTÓRIA DE EMPRESAS,7; ENCONTRO DE PÓS-GRADUAÇÃO EM HISTÓRIA ECONÔMICA, 9, 2019, Ribeirão Preto. Anais [...]. Ribeirão Preto: USP/ABPHE, 2019. 
GOEBEL, M. A. et al. Recuperação judicial e falência das agroindústrias canavieiras no Estado do Paraná. Revista Brasileira de Gestão e Desenvolvimento Regional, Taubaté, v. 16, n. 2, p. 3647, 2020.

GOES, T. H. M. Estratégias de responsabilidade social empresarial (RSE) na agroindústria canavieira paranaense. 2013. Dissertação (Mestrado em Desenvolvimento Regional e Agronegócio) - Universidade Estadual do Oeste do Paraná, Toledo, 2013.

GONÇALVES, J. S.; SOUZA, S. A. M. Proibição da queima de cana no Estado de São Paulo: simulações dos efeitos na área cultivada e na demanda pela força de trabalho. Revista Informações Econômicas, v. 28, n. 3, mar. 1998.

GUIMARÃES, L. S. P. Dinâmica espacial da cana-de-açúcar no Brasil contemporâneo. 2009. Disponível em: https://www.mma.gov.br/estruturas/PZEE/_arquivos/28_10122008091059.pdf. Acesso em: 12 set. 2020.

IBGE. Geociências. Rio de Janeiro: IBGE, 2020. Disponível em: https://www.ibge.gov.br/geociencias/downloads-geociencias.html. Acesso em: 14 ago. 2020.

IBGE. Produção agrícola municipal. Rio de Janeiro: IBGE, 1975.

IBGE. Produção agrícola municipal. Rio de Janeiro: IBGE, 1985.

IBGE. Produção agrícola municipal. Rio de Janeiro: IBGE, 1995.

IBGE. Produção agrícola municipal. Rio de Janeiro: IBGE, 2005.

IBGE. Produção agrícola municipal. Rio de Janeiro: IBGE, 2018.

IPARDES. Base de dados do estado. Curitiba, 2020. Disponível em: http://www.ipardes.pr.gov.br/ imp/index.php. Acesso em: 18 ago. 2020.

IPEA. Infraestrutura social e urbana no Brasil: subsídios para uma agenda de pesquisa e formulação de políticas públicas. v. 2. Brasília: IPEA, 2010.

ITCG. Dados e informações geoespaciais temáticos. Curitiba, 2020. Disponível em: http://www. itcg.pr.gov.br/. Acesso em: 15 set. 2020.

JANNUZZI, F. Território da cachaça: Morretes - Paraná. Mapa da Cachaça, Moema, 2019. Disponível em: https://www.mapadacachaca.com.br/artigos/territorios-da-cachaca-morretes-parana/. Acesso em: 12 set. 2020.

LIMA, J. F. de; PITAGUARI, S. O. As ideias keynesianas e o crescimento do produto nas economias locais. Revista Internacional de Desenvolvimento Local, v. 6, n. 10, p. 11-20, mar. 2005.

MARSDEN, T. et al. Constructing the countryside. Londres: UCL Press Limited, 1993.

MELO, C. O. de; ESPERANCINI, M. S. T.; SILVA, G. H. da. Sazonalidade de preços da cana-de-açúcar no Estado do Paraná. In: CONGRESSO DA SOCIEDADE BRASILEIRA DE ECONOMIA, ADMINISTRAÇÃO E SOCIOLOGIA RURAL (SOBER), 46, 2008, Rio Branco. Anais [...]. Rio Branco: SOBER, 2008.

MENEGUETTI, C. C.; MEZAROBA, S.; GROFF, A. M. Fatores relacionados ao cultivo da cana-de-açúcar. In: ENCONTRO DE ENGENHARIA DE PRODUÇÃO AGROINDUSTRIAL, 4, 2010, Campo Mourão. Anais [...]. Campo Mourão: FECILCAM, 2010.

MONTAGNHANI, B. A. Base econômica e desenvolvimento local: estudo de caso múltiplo em municípios canavieiro. 2012. Dissertação (Mestrado em Desenvolvimento Regional e Agronegócio) - Universidade Estadual do Oeste do Paraná, Toledo, 2012. 
MOREIRA, L. P. L. da S. A corporação Cosan e a conquista de um território em torno de sua usina de etanol em Jataí, Goiás (2007-2012). 2013. Dissertação (Mestrado em Geografia) - Universidade Federal do Rio de Janeiro, Rio de Janeiro, 2013.

OMAR, J. H. D. O papel do Governo na economia. Revista Indicadores Econômicos FEE, Porto Alegre, v. 29, n. 1, p. 211-235, 2001.

PACZYK, R. Setor sucroalcooleiro paranaense: do Proálcool ao biodiesel. Vitrine da Conjuntura, Curitiba, v. 2, n. 6, 2009.

PAIVA, C. Á. Desenvolvimento regional, especialização e suas medidas. Revista Indicadores Econômicos FEE, Porto Alegre, v. 34, n. 1, p. 89-102, jul. 2006.

PAULILLO, L. F. et al. Álcool combustível e biodiesel no Brasil. Revista de Economia e Sociologia Rural, Brasília, v. 45, n. 3, p. 531-565, 2007.

PRIORI, A. et al. A história do oeste paranaense. Maringá: Eduem, 2012.

RAMOS, P. Trajetória e situação atual da agroindústria canavieira do Brasil e do mercado de álcool carburante. In: SANTOS, G. R. dos (org.). Quarenta anos de etanol em larga escala no Brasil: desafios, crises e perspectivas. Brasília: IPEA, 2016. p. 47-83.

SANTOS, G. R. dos (org.). Quarenta anos de etanol em larga escala no Brasil: desafios, crises e perspectivas. Brasília: IPEA, 2016.

SERRA, E. Nordeste do Paraná: o avanço das lavouras de cana e a nova dinâmica do uso do solo nas zonas de contato arenito-basalto. Campo-Território: Revista de Geografia Agrária, Uberlândia, v. 5, n. 9, p. 89-111, 2010.

SHIKIDA, P. F. A. A Evolução diferenciada da agroindústria canavieira no Brasil de 1975 a 1995. 1997. Tese (Doutorado em Economia Aplicada). - Escola Superior de Agricultura "Luiz de Queiroz”, Universidade de São Paulo, Piracicaba, 1997.

SHIKIDA, P. F. A. Evolução e fases da agroindústria canavieira no Brasil. Revista de Política Agrícola, Brasília, v. 23, n. 4, p. 43-57, 2014.

SHIKIDA, P. F. A.; SOUZA, E. C. de. Agroindústria canavieira e crescimento econômico local. Revista de Economia e Sociologia Rural, Brasília, v. 47, n. 3, p. 569-600, 2009.

SHIKIDA, P. F. A; ALVES, L. R. A. Panorama estrutural, dinâmica de crescimento e estratégias tecnológicas da agroindústria canavieira paranaense. Nova Economia, Belo Horizonte, v. 11, n. 2, p. 123-150, 2001.

SPERS, E. E.; Qualidade e segurança em alimentos. In: ZYLBERSZTAJN, D.; NEVES, M. F. (org.). Economia e gestão dos negócios agroalimentares. São Paulo: Pioneira, 2002. p. 283-323.

SZMRECSÁNYI, T. O planejamento da agroindústria canavieira do Brasil (1930-1975). São Paulo: Hucitec/Unicamp, 1979.

SZMRECSÁNYI, T.; MOREIRA, E. O desenvolvimento da agroindústria canavieira do Brasil desde a Segunda Guerra Mundial. Revista Estudas Avançados, São Paulo, v. 5, n. 11, p. 57-79, 1991.

TETTI, L. M. R. Protocolo de Kyoto: oportunidades para o Brasil com base em seu setor sucroalcooleiro: um pouco da história da questão "mudanças climáticas e efeito estufa". In: MORAES, M. A. F. D. de; SHIKIDA, P. F. A. (org.). Agroindústria canavieira no Brasil. São Paulo: Atlas, 2002. p. 199-214. 
THÉRY, C. H. E. H. Especialização e dinâmicas contemporâneas da agropecuária paranaense. Confins: Revista Franco-Brasileira de Geografia, v. 33, 2017.

TOMASETTO, M. Z. de C.; LIMA, J. F. de; SHIKIDA, P. F. A. Desenvolvimento local e agricultura familiar: o caso da produção de açúcar mascavo em Capanema - Paraná. Interações - Revista Internacional de Desenvolvimento Local, Campo Grande, v. 10, n. 1, p. 21-31, 2009.

TSCHÁ, O. da C. P. et al. Encadeamento produtivo, localização e associação geográfica da agroindústria canavieira no Paraná. Redes, Santa Cruz do Sul, v. 15, n. 1, p. 128-155, jan./abr. 2010.

USACUCAR (Usina Santa Terezinha). Unidades de produção. Maringá, 2020. Disponível em: https://www.usacucar.com.br/usacucar.php\#menu. Acesso em: 04 out. 2020.

VIAN, C. E. F.; GONÇALVES, D. B. Modernização empresarial e tecnológica e seus impactos na organização do trabalho e nas questões ambientais na agroindústria canavieira. Revista Economia Ensaios, Uberlândia, v. 22, n. 1, 2007.

VIEIRA, G.; SIMON, E. J. Possíveis impactos da mecanização no corte da cana-de-açúcar, em consequência da eliminação gradativa da queima da palha. In: CONGRESSO BRASILEIRO DE ECONOMIA E SOCIOLOGIA RURAL (SOBER), 43, 2005, Ribeirão Preto. Anais [...]. Ribeirão Preto: SOBER, 2005. 